\title{
Philosophiques
}

\section{Index du volume $\mathrm{V}$}

Volume 5, numéro 2, octobre 1978

URI : https://id.erudit.org/iderudit/014441ar

DOI : https://doi.org/10.7202/014441ar

Aller au sommaire du numéro

\section{Éditeur(s)}

Société de philosophie du Québec

ISSN

0316-2923 (imprimé)

1492-1391 (numérique)

Découvrir la revue

Citer ce document

(1978). Index du volume V. Philosophiques, 5(2), 417-418.

https://doi.org/10.7202/014441ar

Ce document est protégé par la loi sur le droit d'auteur. L'utilisation des services d'Érudit (y compris la reproduction) est assujettie à sa politique d'utilisation que vous pouvez consulter en ligne.

https://apropos.erudit.org/fr/usagers/politique-dutilisation/
Cet article est diffusé et préservé par Érudit.

Érudit est un consortium interuniversitaire sans but lucratif composé de l’Université de Montréal, l'Université Laval et l'Université du Québec à Montréal. Il a pour mission la promotion et la valorisation de la recherche. https://www.erudit.org/fr/ 


\section{INDEX DU VOLUME V}

\section{ARTICLES}

J. BÉLANGER, Images et réalités du behaviorisme.......

P. GRAVEL, Pour une logique de l'action tragique: Hegel et la tragédie ......................... 111

M. HENRY, Qu'est-ce que cela que nous appelons la vie?

R. HOUDE, Á propos (réflexions) .....................

N. KATTAN, Ontologie, esthétique et auvre d'art littéraire .................................... 261

J.N. KAUFMANN, Contributions de l'école de Francfort à la "théorie » des idéologies ................. 229

Y. LAFRANCE, Aristote et l'analyse géométrique ....... 271

J. LEROUX, Concept de théorie et contexte diachronique. 251

R. MONTPETIT, L'esthétique de Rodolphe de Repentigny et la phénoménologie ..........................

\section{2. ÉTUDES CRITIQUES}

A. GOMBAY, La structure performative $d u$ langage juridique, par Georges Legault ..............

G.-A. LEGAULT, Réponses au commentaire de M. André Gombay sur "La structure performative $d u$ langage juridique ".........................

R. MONTPETIT, Réponses au commentaire de Claude Panaccio sur "Comment parler de la littéra-

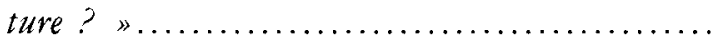

C. PANACCIO, Comment parler de la littérature? par Raymond Montpetit.....................

\section{BULLETIN}

P. LABERGE, Dix années d'études canadokantiennes .... 


\section{INTERVENTIONS}

M. BÉDARD, Pbilosopbie et culture générale ........... 381

J. BOULAD AYOUB, Présentation ................... 179

F. COUTURIER, Le pays de la culture ............... 195

Y. GAUTHIER, Réplique à Pierre Raymond ........... 192

G. LEROUX, La recherche et le comité de déontologie à l'université ............................... 200

R. PELLERIN, Réflexion et responsabilité sociale....... 397

P. RAYMOND, Les " interdictions philosophiques »... 181

P. RAYMOND, Réponse à Yvon Gauthier ......... 189 